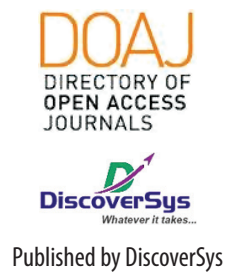

Published by DiscoverSys

\section{Prevalence of risk factors associated with hypertension at Sanglah General Hospital, Bali}

\author{
Mahen Isaac Pannir Chelvam, ${ }^{1 *}$ I Wayan Sugiritama, ${ }^{2}$ \\ I Gusti Nyoman Kamasan Arijana²
}

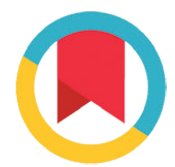

CrossMark

\section{ABSTRACT}

Background: High blood pressure, also called "hypertension," is a serious medical condition. It happens when the force of the blood pumping through the arteries is too strong. The World Health Organization rates hypertension as one of the most important causes of premature death worldwide, and the problem is growing. This study aimed to determine the risk factors affecting Hypertension at Sanglah general hospital.

Methods: This study was a descriptive study with a cross-sectional approach. The data used in this study is a secondary data collected from medical record of the patients with Hypertension at Sanglah general hospital, Denpasar, Bali in the year of 2015 until 2016. The data was categorized based on Body Mass Index (BMI), gender, age, alcohol consumption, and history of cardiovascular diseases.

Results: There are $73(60.83 \%)$ males and $47(39.17 \%)$ females, the majority of patients were in the age group of $18-70$ years of age with the age group of 40 - 50 carrying a rather large quantity of $45.8 \%$ among the male gender and for the female gender the age group of
$51-60$ showed the highest percentage of $38.2 \%$, the sample consists of $60.83 \%$ of males and 39.17 of females from the total 120 samples taken from Sanglah general hospital. As for Body Mass Index (BMI), 25 - 29.9 has the most significant value of 49 (40.83\%) when compared to the other nutritional statuses present. The patients with the cardiovascular disease showed a very substantial amount of 69 (57.5\%) among males and 41 (34.17\%) among females. Patients with a history of alcohol consumption for the male gender had a value of $34(28.30 \%)$, and for the female gender group, it carried an amount of 2 (1.70\%).

Conclusions: This study succeeded in identifying 120 samples of patients with hypertension and their contributing risk factors. The majority of the Samples were with body mass index (BMI) 25 $29.9(40.83 \%)$. The samples with a history of cardiovascular disease showed a value of 69 (57.5\%) among males and 41 (34.17\%) among females. Patients with a history of alcohol consumption for the male gender had a value of 34 (28.30\%), and for the female gender group, it carried an amount of 2 (1.70\%)

Keywords: hypertension, body mass index, risk factor

Cite This Article: Chelvam, M.I.P., Sugiritama, I.W., Arijana, I.G.N.K. 2020. Prevalence of risk factors associated with hypertension at Sanglah General Hospital, Bali. Intisari Sains Medis 11(1): 405-409. D0I: 10.15562/ism.v11i1.510

\section{INTRODUCTION}

Blood pressure is determined both by the amount of blood your heart pumps and the amount of resistance to blood flow in the arteries. The more blood the heart pumps and the narrower the arteries, the higher your blood pressure. High blood pressure, also called "hypertension," is a serious medical condition. It happens when the force of the blood pumping through the arteries is too strong. A study by Markus McGill for the Medical News Today stated that Hypertension is having a blood pressure higher than 140 over $90 \mathrm{mmHg}$, a definition shared by all the medical guidelines. It means the systolic reading (the pressure as the heart pumps blood around the body) is over $140 \mathrm{mmHg}$ (millimetres of mercury) or the diastolic reading (as the heart relaxes and refills with blood) is over $90 \mathrm{mmHg}$. The number of people living with hypertension (high blood pressure) is predicted to be 1.56 billion worldwide by the year 2025. In the US, around 75 million people have hypertension, with more people dying of hypertension-related cardiovascular disease than from the next three deadliest diseases combined. ${ }^{1}$ According to the Singapore National Health Survey (1998), 27.3\% of Singaporeans between the ages of 30 and 69 years, suffer from hypertension. A study by WHO stated that in the Philippines, it had a total death of $38.20 \%$ due to hypertension in the World Ranking Calculations. ${ }^{2}$

According to the latest WHO data published in May 2014, Hypertension Deaths in Indonesia reached 42,226 or $3.02 \%$ of total deaths. The age-adjusted Death Rate is 25.26 per 100,000 of population ranks Indonesia number in the world with increasing counts. 3 Hypertension to this date falls at the 9th place of the 50 causes of death in Indonesia. ${ }^{2}$ As an exertion to that, this study is done to know the significance of Hypertension in the nation. Several risk factors are, therefore associated in this study to introduce and serve as a guideline in preventing hypertension in the upcoming years and generations. Among the risk factors discussed are age, body mass index (BMI), gender, alcohol 
consumption, and cardiovascular diseases. The risk factor of age will be deduced by the highest age group prone to hypertension. Body mass index (BMI) will be calculated by the formula of $\mathrm{kg} / \mathrm{m}_{2}$ whereby kilogram $(\mathrm{kg})$ will represent the weight of the sample and meters squared will be the height of the sample. At the same time, the gender risk factor will be discerned into both sexes male and female. Besides that, alcohol consumption, which is another prospect to hypertension, will be seen on how the frequency and volume of alcohol ingested, brings ramification towards hypertension. In the higher-income countries, about 330 million people have hypertension, as do around 640 million in the developing world. Cardiovascular disease also places a significant role as a risk factor towards hypertension. There are at least 970 million people worldwide who have elevated blood pressure. In the developed world, about 330 million people have hypertension, as do around 640 million in the developing world with a $50 \%$ rate of it induced by cardiovascular diseases. The World Health Organization rates hypertension as one of the most important causes of premature death worldwide, and the problem is growing. In 2025 it is estimated there will be 1.56 billion adults living with high blood pressure with risk to ischemic and hemorrhagic strokes. ${ }^{2}$ Hypertension is generally accepted as one of the key modifiable risk factors for the development of cardiovascular diseases and cerebrovascular events. ${ }^{3}$

\section{METHODS}

This study was a descriptive study with a crosssectional approach. This study aimed to determine the risk factors affecting Hypertension at Sanglah general hospital. The data used in this study is a secondary data collected from medical record of the patients with Hypertension at Sanglah general hospital, Denpasar, Bali in the year of 2015 until 2016. One hundred twenty samples were included in this study. The data was categorized based on Body Mass Index (BMI), gender, age, alcohol consumption, and history of cardiovascular diseases. The BMI criteria used in this study is Asian criteria BMI cut (Underweight: <18.5; Normal: 18.5 - 22.9; overweight: 23 - 24.9; Pre-obese: 25 - 29.9; Obese: $\leq 30$; Obese type 1:30 - 40; Obese type 2: $40.1-50$; Obese type $3:>50$. The data were analyzed descriptively.

\section{RESULT}

The characteristic of patients with hypertension at Sanglah general hospital was showed in table 1. The majority of patients were in the age group of $18-70$ years of age with the age group of $40-50$ carrying a rather large quantity of $45.8 \%$ among the male gender and for the female gender the age group of $51-60$ showed the highest percentage of $38.2 \%$. In the context of gender distribution, the sample consists of $60.83 \%$ of males and 39.17 of females from the total 120 samples taken from sanglah hospital. Hypertension was most commonly found among males in the age group of between 40 to 50 years of age. Though females showed a significantly lower amount compared to males, the highest number of females with hypertension was found in the age group $51-60$ with an amount of about $38.2 \%$ the age group of $51-60$ is the second-highest for the male population with a percentage of $30.0 \%$, and as for females the age group of $40-50$ is second highest with a percentage of $35.2 \%$. Age group $61-70$ has a dispersal of $10.1 \%$ for males and $18.2 \%$ for females. The age group with the least number of hypertension patients are $18-28$, with a percentage of $3.8 \%$ respectively for both male and female.

The characteristic of Body mass index (BMI) patients with hypertension at Sanglah general hospital based on Asian criteria was showed in table 2. According to the table, the overweight nutritional status which carries the body mass index (BMI) of $25-29.9$ has the most significant value of $49(40.83 \%)$ when compared to the other nutritional statuses present. The normal category nutritional status showed a fair amount of 42 (35\%) among the 120 samples. It is also shown in the table that the pre-obese category of the nutritional status carries a staggering amount of $24(20 \%)$ and the obesity category showed the least amount of 5 (4.16\%). For the underweight, obese type 1, obese type 2 and obese type 3 categories, it all showed null percentage respectively.

The patients present with the cardiovascular disease showed a very significant value of 69 (57.5\%) among males and 41 (34.17\%) among females as compared to the patients without cardiovascular diseases whereby in the male population the value was rather declined, carrying an amount of $4(3.33 \%)$ among the male patients and $6(5 \%)$ among the female patients. It is rather evidential that cardiovascular diseases are a significant factor in contributing to Hypertension (table 3). The history of alcohol consumption of patients was shown in table 4.

\section{DISCUSSION}

In comparison to a journal by American Hypertension Society, researched by Brian Gribbin et al., which studied the effects of age and High Blood Pressure, which was conducted on 61 samples, 31 males and 20 females, in regards 
Table 1 The characteristic of patients with hypertension at Sanglah general hospital

\begin{tabular}{lccc}
\hline Age Group (years) & Male (\%) & Female (\%) & Total $(\mathbf{n = 1 2 0})$ \\
\hline $18-28$ & 3.8 & 3.8 & 4 \\
$29-39$ & 10.3 & 4.6 & 22 \\
$40-50$ & 45.8 & 35.2 & 42 \\
$51-60$ & 30.0 & 38.2 & 37 \\
$61-70$ & 10.1 & 18 & 15 \\
\hline
\end{tabular}

Table 2 Body Mass Index (BMI) patients with hypertension at Sanglah general hospital Based on Asian Criteria

\begin{tabular}{lcc}
\hline Age Group (years) & Asian Criteria BMI cut & Total (\%) \\
\hline Underweight & $<18.5$ & 0 \\
Normal & $18.5-22.9$ & $42(35 \%)$ \\
Overweight & $23-24.9$ & $49(40.83 \%)$ \\
Pre-Obese & $25-29.9$ & $24(20)$ \\
Obese & $\leq 30$ & $5(3.16$ \\
Obese type 1 & $30-40$ & 0 \\
Obese type 2 & $40.1-50$ & 0 \\
Obese type 3 & $>50$ & 0 \\
\hline
\end{tabular}

Table 3 Patients with a history of cardiovascular diseases

\begin{tabular}{lcc}
\hline Cardiovascular Disease & Gender & Total \\
\hline With Cardiovascular disease & Male & $69(57.5 \%)$ \\
& Female & $41(34.17 \%)$ \\
Without Cardiovascular disease & Male & $4(3.33 \%)$ \\
& Female & $6(5 \%)$ \\
\hline
\end{tabular}

Table 4 Patients with a Previous History of Alcohol Consumption

\begin{tabular}{lcc}
\hline History of Alcohol Consumption & Gender & Total \\
\hline With a history of alcohol consumption & Male & $69(57.5 \%)$ \\
& Female & $41(34.17 \%)$ \\
Without a history of alcohol consumption & Male & $4(3.33 \%)$ \\
& Female & $6(5 \%)$ \\
\hline
\end{tabular}

to showing how different age groups affect the chances of acquiring Hypertension, it is shown that the risk of hypertension increases with age. In the study, a baroreflex was used to measure and regulate blood pressure at the slight elevation of pressure, with that, it is seen that the need for regulation elevated alongside age groups. Similarly, when compared to the result of the discussion, it is understood that for the male category the highest data was seen in the age group of $40-50$ which can most commonly be expressed as the productive age for men. Hypertension could have been caused by the stress and workload carried along with the male category at that group of age. ${ }^{4}$ In another study conducted by the Americal Health Association, led by Ramachandran S. Vasanth et al., entitled, Residual Lifetime Risk of Developing Hypertension in Middle-Aged male and female, it is shown that during the two years, 1298 participants (598 men and 709 females) provided 8469-person-years observation. The residual lifetime risk for developing hypertension was similar for men and woman. It did not differ between participants aged 55 and 75 years of age (hazards ratio) [HR] for woman vs men aged 55 years, 0.91 ]95\% CI, 0.80-1.04]; for those aged 65 years, 0.88 [95\% CI 0.76-1.04]) More the half of the 55-year-old participants and about two-thirds of the 50 -55-year-old populations developed hypertension within ten years. Though this slightly varied from the results obtained at the Sanglah Hospital, it carries a significance that the age group of 50 to 65 is very prone to Hypertension and should be cared for. ${ }^{5}$

In another journal by the International Epidemiology Journal, conducted by Anne Fagot Campagna, bearing the title, High free fatty acid concentration: an independent risk factor for hypertension in the Paris Prospective Study, by means that 2968 non-hypertensive and nondiabetic Caucasian men were followed for three years. 6 Hypertension incidence was defined as systolic blood pressure (SBP) ${ }^{*} 160 \mathrm{mmHg}$ or diastolic blood pressure (DBP) $5^{\star} 95 \mathrm{mmHg}$ or drug treatment for hypertension. Results obtained were, Free fatty acid elevation was a highly significant risk factor for hypertension when controlled for age, family history of hypertension, alcohol consumption, body mass index, iliac circumference, and weight change. Further controlling for SBP, heart rate and fasting insulin and glucose did not decrease its predictive power (hazard rate ratio $[R R]=1.58,95 \%$ confidence interval $[\mathrm{CI}]: 1.30$ 1.91 comparing the 90th to the 10th percentiles at fasting; $\mathrm{RR}=1.54,95 \% \mathrm{CI}: 1.33-1.79$ at two $\mathrm{h}$ ). In a forward stepwise model controlled for age, family history of hypertension, alcohol consumption and SBP, the selected variables explaining the occurrence of hypertension were, in order, weight change, 2-h free fatty acids, iliac circumference and fasting free fatty acids, whereas body mass index, heart rate, insulin, glucose, and other lipids did not enter into the model. Free fatty acids elevation is a risk factor for hypertension. ${ }^{6}$

Another study by the Hypha Organization conducted by Gung Ho Noel et al., entitled Relationship of Physical Activity and Body Mass Index to the Risk of Hypertension: A Prospective Study in Finland it is reflected that results showed that prospective studies on physical activity about 
the risk for hypertension are scant, particularly in women. ${ }^{7}$ This study was finding out whether regular physical activity can reduce the risk of hypertension in both men and women, and in subjects with and without overweight. The study prospectively followed 8302 Finnish men and 9139 women aged 25 to 64 years without a history of antihypertensive drug use, coronary heart disease, stroke, and heart failure at baseline. Both single and joint associations of physical activity and body mass index with the risk of hypertension were examined using Cox proportional hazard models. During a mean follow-up of 11 years, there were 1600 incident cases of drug-treated hypertension. Multivariateadjusted hazards ratios of hypertension associated with light, moderate, and high physical activity were $1.00,0.63$, and 0.59 in men (Ptrend_0.001), and $1.00,0.82$, and 0.71 in women (Ptrend_0.005), respectively. This association persisted both in subjects who were overweight and in those who were not. Multivariate-adjusted hazards ratios of hypertension based at different levels of body mass index ( $\_25,25$ to 29.9 , and _30) were $1.00,1.18$, and 1.66 for men (Ptrend_0.001), and 1.00, 1.24, and 1.32 for women (Ptrend_0.007), respectively. Further adjustment for baseline systolic blood pressure did not affect the protective effect associated with physical activity, but it weakened the association between body mass index and hypertension markedly. Regular physical activity and weight control can reduce the risk of hypertension. ${ }^{7}$ Study conducted by Bhargah using a quasi-experimental model with pre-test and post-test group design involving 28 elderly performed aerobic exercise through a healthy heart gymnastics exercise with a duration of 45 minutes. There was a decrease in systolic blood pressure of $19 \mathrm{mmHg}$ (post-exercise $(121.96 \pm 1.43 \mathrm{mmHg})$ compared with baseline $(141.35 \pm 8.76)(\mathrm{p}<0.001))$, diastolic as much as $11 \mathrm{mmHg}$ (post-exercise $(121.96 \pm 1.43 \mathrm{mmHg}$ ) compared with baseline $(91.75 \pm 1.48)(\mathrm{p}<0.001))$, and MAP of $14 \mathrm{mmHg}$ (post-exercise (93.89 \pm $1.15 \mathrm{mmHg}$ ) compared with baseline $(108.39 \pm 1.34)$ $(\mathrm{p}<0.001))$ in condition before and after 60 minutes of aerobic exercise. ${ }^{8}$

A study by Howard D. Senso for the AHA Journals, titled Alcohol Consumption and the Risk of Hypertension in Women and Men, subjects reported current alcohol intake by responding to a question on how often they consumed alcoholic beverages, without regard to the amount of alcohol consumption for each episode and these responses were interpreted as the number of drinks consumed in the specified period, converting seven response categories (rarely or never, 1 to 3 per month, 1 per week, 2 to 4 per week, 5 to 6 per week, daily, and 2 per day) to the number of alcoholic drinks consumed weekly $(0.0,0.5,1.0,3.0,5.5,7.0$, and 18.0 drinks per week, respectively). Results obtained were in women, total alcohol intake was summed from liquor, red wine, white wine, and beer; men reported total alcohol intake from a single combined question.9 During 10.9 and 21.8 years of follow-up, 8680 women and 6012 men developed hypertension (defined as new physician diagnosis, antihypertensive treatment, reported systolic blood pressure _140 mm Hg, or diastolic blood pressure _90 $\mathrm{mm} \mathrm{Hg}$ ). In women, we found a J-shaped association between alcohol intake and hypertension in age- and lifestyle-adjusted models. In men, alcohol intake was positively and significantly associated with the risk of hypertension and persisted after multivariate adjustment. Models stratified by baseline systolic blood pressure (120 versus _120 mm Hg) or diastolic blood pressure (_75 versus _ $75 \mathrm{~mm} \mathrm{Hg}$ ) did not alter the relative risks in women and men. In conclusion, the threshold above which alcohol became deleterious for hypertension risk emerged at_ 4 drinks per day in women versus a moderate level of _1 drink per day in men. ${ }^{9}$

A study for the Journal of Cardiovascular Pharmacology, by William B Kennel, showed that the chief hazards atherosclerosis and coronary disease. 9 The risk of hypertension is concentrated with a high total/high-density lipoprotein (HDL)cholesterol ration, impaired glucose tolerance, high fibrinogen, and electrocardiographic (ECG) abnormalities. Among suggested measured were a close watch to blood lipids, left ventricular hypertrophy, stroke, peripheral arterial disease, cardiac failure, or any other cardiovascular event. As compared to the study, cardiovascular disease was a significant contributor to the occurrence of Hypertension and should be closely watched in the prevention of Hypertension in the coming years. ${ }^{10}$

\section{LIMITATION}

The limitations that were sustained during this study was a lack in the medical record at Sanglah general hospital, which was a secondary data in this study. Thus, there was a little insufficiency in previous record history.

\section{CONCLUSION}

This study succeeded in identifying 120 samples of patients with hypertension and their contributing risk factors. Among the risk factors discussed are age, body mass index (BMI), gender, alcohol 
consumption, and cardiovascular diseases. The age group of 40 - 50 carrying a rather large quantity of $45.8 \%$ among the male gender and for the female gender the age group of $51-60$ showed the highest percentage of $38.2 \%$. As for body mass index (BMI), $25-29.9$ has the most significant value of 49 (40.83\%). The patients present with the cardiovascular disease showed a very substantial amount of 69 (57.5\%) among males and 41 (34.17\%) among females. Patients with a history of alcohol consumption for the male gender had a value of $34(28.30 \%)$, and for the female gender group, it carried an amount of $2(1.70 \%)$.

\section{ETHICAL CLEARANCE NUMBER}

This study has been obtained the ethics approval from the Faculty of Medicine, Udayana University, Sanglah General Hospital, Bali, Indonesia.

\section{CONFLICT OF INTEREST}

The author states that there is no conflict of interest regarding the publication of this article.

\section{FUNDING}

This research does not get funding provided by the government or other private institutions.

\section{AUTHOR CONTRIBUTION}

Research concept: Mahen Isaac Pannir Chelvam, I Wayan Sugiritama, I Gusti Nyoman Kamasan Arijana. Data collection, data input, and data processing: Mahen Isaac Pannir Chelvam. Preparation of Research manuscript: Mahen Isaac Pannir Chelvam.

\section{REFERENCES}

1. MacGill, M. Hypertension: Causes, symptoms, and treatments. MediLexicon International Limited. 2015.

2. WHO. A global brief on Hypertension: silent killer, global public health crises (World Health Day 2013). Geneva: WHO. 2013.

3. Pertiwi GAR, Aryawangsa AAN, Prabawa IPY, Manuaba IBAP, Bhargah A, Ratni NWS, Budiana IPG. Factors associated with visit-to-visit variability of blood pressure in hypertensive patients at a Primary Health Care Service, Tabanan, Bali, Indonesia. Family Medicine and Community Health. 2018;6(1):191-199.

4. Brian G., Thomas GP. Effects of Age and High Blood Pressure on Baroreflex Sensitivity in Man. [Online] Volume 29. (Uploaded 1971) Available on http://circres. ahajournals.org/.

5. Ramachandran S. Vasan., Alexa B., Sudha S., et al. Residual Lifetime Risk for Developing Hypertension in Middleaged Women and Men. [Online] doi:10.1001. (Uploaded 2002) Available on http://jamanetwork.com/journals.

6. Anne FC., Beverley B., et al. High free fatty acid concentration: an independent risk factor for hypertension in the Paris Prospective Study. [ Online] 10.1093 (Uploaded 2000) Available on http://ije.oxfordjournals.org.

7. Gang H., Noël CB., Jaakko T., Timo AL., Aulikki N., Pekka J. Relationship of Physical Activity and Body Mass Index to the Risk of Hypertension: A Prospective Study in Finland. [Online] Volume 43. Issue 1 (Uploaded 2004) Available on http://hyper.ahajournals.org.

8. Bhargah A, Muliarta M, Prabawa IPY, Manuaba IBAP, Bhargah V. Post-Exercise Hypotension Phenomenon in Elderly after Aerobic Exercise. Journal of Global Pharma Technology. 2018; 10(6):323-327.

9. Howard D., Sesso NR., Cook JE., Buring JE., Manson J., Michael G. Alcohol Consumption and the Risk of Hypertension in Women and Men. [Online], Volume 51, Issue 4 (Uploaded 2008). Available on http://hyper. ahajournals.org.

10. William B. Kannel. Blood Pressure as a Cardiovascular Risk Factor. [Online] Vol 68 79-96 (Uploaded 2010). Available on http://digitaljournals.org.

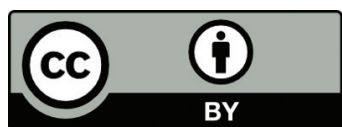

This work is licensed under a Creative Commons Attribution 